This is an open access article under the CC BY-NC-ND license (https://creativecommons.org/licenses/by-nc-nd/3.0/) Issue III, November 2020

ISSN 2707-9481

ISBN 978-601-323-207-2

https://doi.org/10.31643/2020.034

Feruza Fuzaylova

Institute of General and Inorganic Chemistry of the

Academy of Sciences of the Republic of Uzbekistan

Email: ionxanruz@mail.ru

ORCID ID https://orcid.org/0000-0003-1975-0947
Vitaliy P. Guro

Institute of General and Inorganic Chemistry of the

Academy of Sciences of the Republic of Uzbekistan

Email: ionxanruz@mail.ru

ORCID ID https://orcid.org/0000-0001-5765-0408

\title{
Development of Solutions for Chemical Phosphating of Carbon Steel
}

\begin{abstract}
A consumer in Uzbekistan imports concentrates phosphating the surface of carbon steels, such as, for example, Foscon 35 and Foscon 35K. (Russia). Work has been done to create analogs from local raw materials. Having studied the physicochemical properties of the concentrates, a mechanism for the formation of protective phosphate coatings was suggested, and the components of a new phosphating composition were selected. The aim of the work was to develop a composition of a solution for chemical phosphating of the surface of carbon steel at the local resource base. Methods used: elemental chemical analysis, electrochemical and corrosion measurements, conditionally total acidity of solutions was measured according to TU 2149-205-10964029-2004 (Russia). The effect of temperature, $\mathrm{pH}$ of the medium, and the exposure time of the sample in the phosphating solution on the quality of the phosphate film was studied. As a result, a phosphating composition FK-1 was developed, functionally similar to imported concentrates Foscon 35 and Foscon 35K, based on local raw materials.
\end{abstract}

Keywords: carbon steel, surface, chemical phosphating, protective properties, phosphate coating.

Cite this article as: Fuzaylova F., Guro V. P. (2020). Razrabotka Rastvorov Khimicheskogo Fosfatirovaniya Uglerodistoy Stali [Development of Solutions for Chemical Phosphating of Carbon Steel]. Challenges of Science. Issue III, p.: 215-218. (In Russian). https://doi.org/10.31643/2020.034

Феруза Фузайлова

Институт общей и неорганической химии Академии наук Республики Узбекистан

Email: ionxanruz@mail.ru

ORCID ID https://orcid.org/0000-0003-1975-0947
Виталий П. Гуро

Институт общей и неорганической химии Академии наук Республики Узбекистан

Email: ionxanruz@mail.ru ORCID ID https://orcid.org/0000-0001-5765-0408

\section{Разработка Растворов Химического Фосфатирования Углеродистой Стали}


Абстракт. Потребитель в Узбекистане импортирует фосфатирующие поверхность углеродистых сталей концентраты, такие как, Фоскон 35 и Фоскон 35К (РФ). Проведена работа по созданию аналогов, из местного сырья. Изучив физико-химические свойства концентратов, предположен механизм формирования защитных фосфатных покрытий, а также подобраны компоненты нового фосфатирующего состава. Целью работы была разработка на местной сырьевой базе состава раствора химического фосфатирования поверхности углеродистой стали. Использованы методы: элементного химического анализа, электрохимических и коррозионных измерений, условно-общая кислотность растворов измерялась по ТУ 2149-205-10964029-2004 (РФ). Изучено влияние температуры, рН среды, времени выдержки образца в растворе фосфатирования на качество фосфатной пленки. В итоге, разработан фосфатирующий состав ФК-1, функционально аналогичный импортным концентратам Фоскон 35 и Фоскон 35К, на основе местного сырья.

Ключевые слова: углеродистая сталь, поверхность, химическое фосфатирование, защитные свойства, фосфатное покрытие.

\section{Введение}

В строительстве и ряде других отраслей промышленности востребованы металлоконструкции и оборудование из углеродистой стали, покрытой на этапах межоперационной защиты, подготовки к деформации и окраске, фосфатным покрытием. Его наносят в растворах химического фосфатирования (Ажогин, Ф.Ф. 1987), приготовленных из концентратов [1]. В Узбекистан они поступают из-за границы, например, России (Фоскон 35 и Фоскон 35К) (Бонокина, М.Н. 2009) [2]. С учетом данных публикаций [3], (Ягубова, В.Л. 2010) [4], изучения сырьевой базы производства таких концентратов, проведено исследование способов составления цинк-нитрат-фосфатных концентратов из местного сырья, их защитных свойств (Фузайлова, Ф.Н. 2020) [5].

\section{Методы и материалы}

Измерения физико-химических показателей концентратов и растворов фосфатирования на их основе - растворов Фоскон-35 (Россия), ФК-1 (Узбекистан), согласно ТУ 2149-205-10964029-2004 (РФ), выполнены на заводе-потребителе «ЦПиРС СП ООО ТТЗ имени В.Л. Гальперина» (Узбекистан). Сравнительные испытания фосфатных покрытий проведены на основе методов: 1) измерения скорости коррозии, по ГОСТ 28084-89; 2) «капли и погружения» в раствор №38 по ГОСТ 9.302-88, с выдержкой не менее 90 сек, до цвета контактной меди; 3) поляризационное сопротивление $R n$ измерялось мостом переменного тока Р-5035; электрический потенциал поверхности стали марки Ст.10 измерялся относительно х.с.э. на потенциостате ПИ-50-1. Контроль компонентов растворов: фосфора, в пересчете на $\mathrm{P}_{2} \mathrm{O}_{5}$, по ГОСТ 13493-86, цинка и нитрат-ионов - методами элементного анализа.

\section{Результаты и их обсуждение}

Известен фосфатирующий состав, г/л: ионы цинка $\left(\mathrm{Zn}^{2+}\right) 5,55-18,72$; фосфорный ангидрид $\left(\mathrm{P}_{2} \mathrm{O}_{5}\right) 4,35-15,68$; нитрат $\left(\mathrm{NO}_{3}^{-}\right)$9,25-33,6; натрий $\left(\mathrm{Na}^{+}\right)$0,56-2,46; ионы аммония $\left(\mathrm{NH}_{4}^{+}\right)$0,19-0,82. Его недостатки: низкие защитные свойства при контроле по п. 6.2. ГОСТ 9.302-88; образование помутнения из гидроксидов цинка, свидетельствующего о несбалансированном составе раствора по ионам цинка и фосфат-ионам и о нецелевом расходе сырья. Задачей работы стало создание раствора фосфатирования стали с высокими защитными свойствами и устранением недостатков, связанных с несбалансированным составом и нецелевым перерасходом сырья. Представляло интерес сравнить защитные свойства покрытий из раствора фосфатирования на основе ФК-1 и 14,8\% раствора концентрата Фоскон 35, при температуре 40 и $75{ }^{0} \mathrm{C}$ методом «капли и погружения» ГОСТ 9.302-88; при контроле показателя $\mathrm{K}$ - отношения площади образца $\mathrm{S}$, дм², к объему раствора $\mathrm{V}$, дм ${ }^{3}$ (табл. 1). 
Таблица 1. Результат оценки защитных свойств покрытий из растворов на основе ФК-1 и Фоскон 35 (концентрация обоих 14,8\%), показатель К=1.

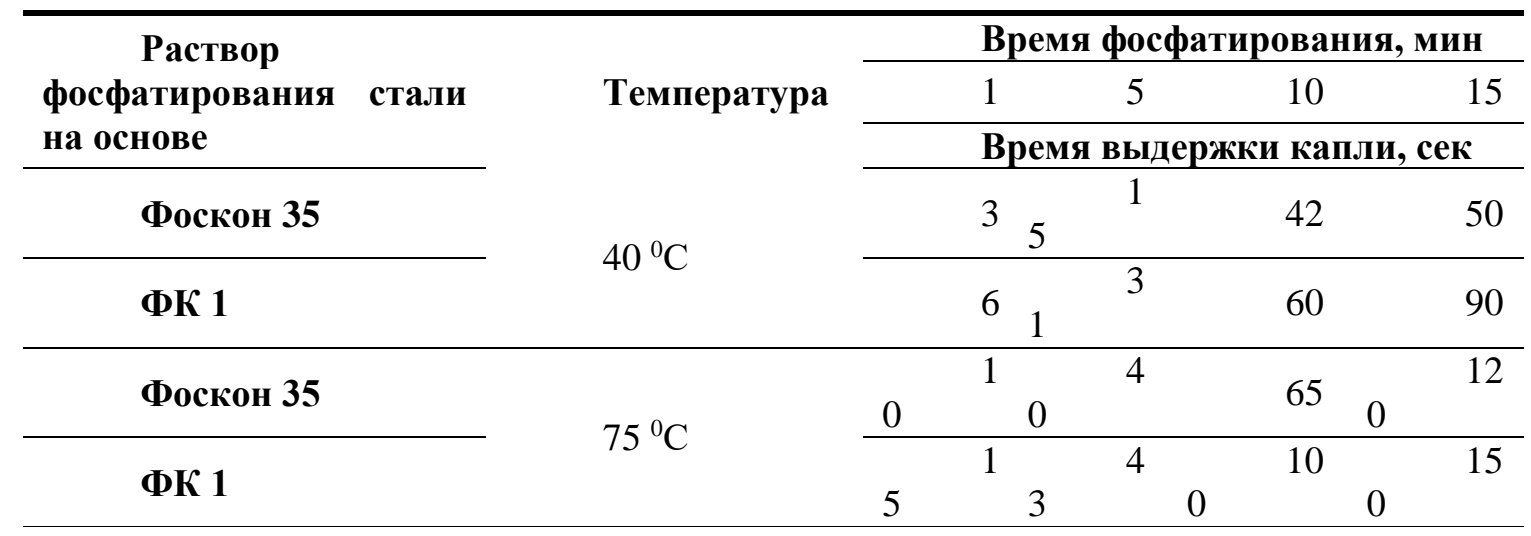

Из табл. 1 видно, что нагрев растворов, с 40 до $75{ }^{\circ} \mathrm{C}$ положительно влиял на защитные свойства покрытий (время выдержки капли увеличилось) из растворов обоих типов. Однако, сравнение этого показателя для них выявил преимущество ФК-1, как при 40, так и 75 ' $\mathrm{C}$ : время выдержки капли на фосфатной пленке, созданной в растворе ФК-1 больше, чем в Фоскон 35.

Представляло интерес сравнить аналогичное поведение тех же растворов, но только при $75^{0} \mathrm{C}$ и переменном показателе К (табл. 2).

Таблица 2. Защитные свойства покрытий из растворов на основе ФК-1 и Фоскон 35 (концентрация обоих $14,8 \%$ ) при $75{ }^{\circ} \mathrm{C}$ и переменном показателе К

\begin{tabular}{|c|c|c|c|c|c|c|}
\hline \multirow{3}{*}{$\begin{array}{c}\text { Раствор } \\
\text { фосфатирования } \\
\text { стали на основе }\end{array}$} & \multirow{3}{*}{ 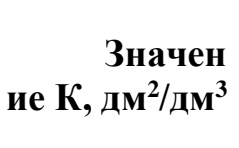 } & \multicolumn{5}{|c|}{ Время фосфатирования,мин } \\
\hline & & & 1 & 5 & 10 & 15 \\
\hline & & \multicolumn{5}{|c|}{ Время выдержки капли, сек } \\
\hline Фоскон 35 & \multirow{2}{*}{0,5} & & 4 & 15 & 38 & 52 \\
\hline ФК 1 & & & 6 & 21 & 48 & 66 \\
\hline Фоскон 35 & \multirow{2}{*}{2,0} & 8 & 1 & 52 & 87 & 125 \\
\hline ФК 1 & & 4 & 2 & 67 & 174 & 180 \\
\hline Фоскон 35 & \multirow{2}{*}{3,0} & 8 & 2 & 71 & 98 & 176 \\
\hline ФК 1 & & 4 & 4 & 76 & 192 & 200 \\
\hline
\end{tabular}

Из табл. 2 видно, что ряд падения значения К: 3,0-2,0-0,5 иллюстрирует скорость истощения по активным компонентам: чем больше К, тем она меньше и тем выше показатель защитных свойств покрытий: время выдержки «капли» увеличивается из растворов обоих типов. Однако, сравнение этого показателя выявило преимущество ФК1. Для обоснования диапазона рабочих концентраций выполнено сравнение показателей: условно-общей кислотности (КО) «точки» и отношения условнообщей кислотности к свободной кислотности, а также защитная способность фосфатирующих растворов.

\section{Выводы}

Выполнено сравнение защитных свойств фосфатных покрытий из растворов разного состава. В результате, создан раствор фосфатирования, из местного сырья, применение которого обеспечивает устранение недостатков, характерных для импортных аналогов, а именно: - получается качественное 
фосфатное покрытие поверхности изделий из углеродистой стали, с повышенными защитными свойствами в отношении коррозии; - устраняется образование помутнения раствора из-за образования при гидролизе гидроксидов цинка; - снижается себестоимость производства фосфатирующего раствора за счет рационального использования сырья.

Ссылка на данную статью: : Фузайлова Ф.Н., Гуро В.П. (2020) Разработка растворов химического фосфатирования углеродистой стали. Материалы Международной практической интернет-конференции «Актуальные проблемы науки» [Challenges of Science]. Выпуск III, стр. 215 218. https://doi.org/10.31643/2020.034

\section{Литературы}

[1] Ажогин, Ф.Ф., Беленький, М.А. (1987). Гальванотехника. Справочник. - Москва: Металлургия (736).

[2] Бонокина, М.Н., Чумаевский, В.А., Журавлева, С.Л., Маслова, В.И. (2009). Патент RU 2354 747. Способ получения фосфатного покрытия. Патентообладатель: ЗАО "ФК" (RU); Заявлено 2007127364/02, 17.07.2007; Дата выдачи патента: 17.07.2007; Опубликовано: 10.05.2009. Бюллетень 13.

[3] Концентраты фосфатирующие Фоскон-35, Фоскон-35К, Технические условия. ТУ 2149-205-10964029-2004 (Россия), изменение 1, 2, 3.

[4] Ягубова, В.Л., Мирошниченко, Ю.С., Чумаевский, В.А. (2010). Патент RU 2380458. Способ получения цинкнитрат-фосфатного концентрата. Патентообладатель: ЗАО 'ФК' (RU). Заявлено 2008122869/15; 06.06.2008; Опубликовано 27.01.2010. Бюллетень 3.

[5] Фузайлова, Ф.Н., Гуро, В.П., Дадаходжаев, А.Т., Ибрагимова, М.А. (2020). Оценка защитных свойств покрытий углеродистой стали из растворов химического фосфатирования. Узбекский химический журнал, 5. (48-53).

\section{References}

[1] Azhogin, F.F., Belen'kiy, M.A. (1987). Gal'vanotekhnika. Spravochnik [Electroplating. Directory]. - Moskva: Metallurgiya (736). (in Russian).

[2] Bonokina, M.N., Chumayevskiy, V.A., Zhuravleva, S.L., Maslova, V.I. (2009). Patent RU 2354 747. Sposob polucheniya fosfatnogo pokrytiya [A method for producing a phosphate coating]. Patentoobladatel': ZAO "FK" (RU); Zayavleno 2007127364/02, 17.07.2007; Data vydachi patenta: 17.07.2007; Opublikovano: 10.05.2009. Byulleten' 13. (in Russian).

[3] Kontsentraty fosfatiruyushchiye Foskon-35, Foskon-35K, Tekhnicheskiye usloviya. TU 2149-205-10964029-2004 (Rossiya) [Specifications. TU 2149-205-10964029-2004], izmeneniye 1, 2, 3. (in Russian).

[4] Yagubova, V.L., Miroshnichenko, YU.S., Chumayevskiy, V.A. (2010). Patent RU 2380458. Sposob polucheniya tsinknitrat-fosfatnogo kontsentrata [Method of producing zinc-nitrate-phosphate concentrate]. Patentoobladatel': ZAO 'FK' (RU). Zayavleno 2008122869/15; 06.06.2008; Opublikovano 27.01.2010. Byulleten' 3. (in Russian).

[5] Fuzaylova, F.N., Guro, V.P., Dadakhodzhayev, A.T., Ibragimova, M.A. (2020). Otsenka zashchitnykh svoystv pokrytiy uglerodistoy stali iz rastvorov khimicheskogo fosfatirovaniya [Evaluation of protective properties of carbon steel coatings from chemical phosphating solutions]. Uzbekskiy khimicheskiy zhurnal, 5. (48-53). (in Russian). 